\title{
Messages from Japan policy for viral hepatitis
}

\author{
Tatsuya Kanto* \\ The Research Center for Hepatitis and Immunology, National Center for Global Health and Medicine, Ichikawa, Japan.
}

\begin{abstract}
In Japan, the estimated number of chronic HBV infections was 1.1-1.2 million and that of chronic HCV was 0.9-1.3 million in 2015. The mortality of hepatocellular carcinoma (HCC) had been increasing and hit a peak at around 2002, which subsequently started to decrease. Japan has a national action plan for addressing viral hepatitis called, "Basic Act on Hepatitis Measures", established in 2009. "Basic Guidelines for Promotion of Control Measures for Hepatitis" was issued in 2011 and was updated in 2016, comprising 9 principles in order to promote measures to prevent hepatitis B and C. According to these guidelines, national and local government share screening costs for testing HBV and HCV for those residents who are over 40 years old. Thus, out-of-pocket expenses from examinees are free of charge or reduced to a minimum. In addition, for patients with chronic hepatitis $\mathrm{B}$ or $\mathrm{C}$ being treated: drug prices of nucleotide analogues, interferon treatment or direct antiviral agents, and examination expenses should be covered by a special program for viral hepatitis. From December 2018, the special coverage program of medical expenses, shared by central and local government, has started for patients with HBV- or HCV-induced liver cancer and decompensated cirrhosis. However, in the cascade-of-care of viral hepatitis in Japan, significant gaps still remain in the diagnosis, treatment and transition to patients in need. Several advantages have prevailed in Japanese health care systems for patients with viral liver disease compared to those in other countries in the Western Pacific Region. Therefore, Japan should take a lead in helping the implementation of a practical hepatitis action plan for each country in need.
\end{abstract}

Keywords: viral hepatitis, liver cancer, decompensated cirrhosis, Basic Act on Hepatitis Measures

On the globe, approximately 257 million people are infected with hepatitis B virus (HBV) and 71 million with hepatitis $\mathrm{C}$ virus (HCV) as of 2015, respectively (1). Both viruses are hepatotropic and principally of a non-cytopathic nature, and the majority of the endemic areas are in developing countries. Once infected, substantial populations progress to a chronicallyinfected state that eventually develops liver cirrhosis and hepatocellular carcinoma (HCC) within decades. Liver cirrhosis and liver cancer are responsible for $94 \%$ of deaths associated with hepatitis infections. Liver cancer is the second most common cause of cancer deaths in the Asia-Pacific Region, and approximately $78 \%$ of liver cancer causes are a result of chronic viral hepatitis B or C (1). Viral hepatitis is the seventhleading cause of mortality globally, responsible for 1.45 million deaths in 2013 (2). One quarter of the world's population lives in the Western Pacific, but the Region bears $40 \%$ of the world's deaths caused by hepatitis. Consequently, hepatitis kills more than 1,500 people every day in the Region (1).

Regardless of the success of hepatitis B (HB) vaccination, which has reduced the prevalence of HBsAg in the under 5 years old population in several countries, millions of people across the Region still continue to live with chronic hepatitis B or C and the risk of cirrhosis and liver cancer. We now have effective medicines, such as direct acting antivirals (DAAs) and nucleot(s)ide analogues (NAs) to manage and treat chronic hepatitis $\mathrm{C}$ or $\mathrm{B}$, respectively. The high price of DAAs has been a major barrier for access to treatment across the Region. In response to the social movement and WHO's designation of some DAAs as essential medicine, a mega-pharma agreed to tiered pricing and provided generic licensing to several pharmaceutical companies. Currently, generic DAAs are commercially available in designated low- or middle-income countries where people can get access to DAAs at reasonable prices. In order to achieve WHO targets of viral hepatitis elimination by 2030 , various barriers still need to be overcome, depending on the policy and socio-economic circumstances in each country.

In this special topic issue of Global Health \& Medicine, experts from countries in Asia and Pacific contribute reviews covering current status of elimination efforts in the epidemiological, clinical and policy settings in this region. As for a preface, I summarize here the outline of the policy for viral hepatitis in Japan. 


\section{National hepatitis action plan in Japan}

In 2015, the estimated number of individuals with chronic HBV infection was 1.1-1.2 million and that of chronic HCV infection was 0.9-1.3 million in Japan (3). Annual incidence of deaths in 2014 from liver cirrhosis was approximately 10 thousand and that from liver cancer was 29 thousand, respectively. And $70 \%$ of deaths from liver cirrhosis or cancer were caused by hepatitis B and C. Therefore, in Japan, it has been an important health issue for the management and care of patients with chronic hepatitis B or C infection.

Japan has a national plan for addressing viral hepatitis called, "Basic Act on Hepatitis Measures", established in 2009 (Act No.97 of the year 2009) (4). Following 2011, "Basic Guidelines for Promotion of Control Measures for Hepatitis" was issued by the government, comprising 9 principles of measurement, in order to promote prevention of hepatitis B and C (5). There are set targets and government has allocated funding for the plan. The Ministry of Health and Labour and Welfare (MHLW) in Japan has appointed working groups for viral hepatitis, "The Council for Promotion of Hepatitis Measures", including epidemiologists and clinical researchers. Based on "Basic Act on Hepatitis Measures", every prefecture and government have selected linked regional core centers for treatment of liver disease (hereafter referred to as regional core centers) along with achieving cooperation of specialized medical institutions, so that there is no bias by region, and it will be equally improved. Consultation Center for Liver diseases has been installed in all regional core centers corresponding to the consultation from the patient and their family. The Hepatitis Information Center was established in The National Center for Global Health and Medicine (NCGM), The Research Center for Hepatitis and Immunology in 2008. Some of the roles of the Hepatitis Information Center are the support for sharing medical information between regional core centers, the training of medical personnel and the provision and dissemination of up-to-date information regarding hepatitis (6). Along with the update of "Basic Guidelines for Promotion of Control Measures for Hepatitis" in 2016, The Hepatitis Information Center has been assigned to take more responsibility to promote linkage for care of hepatitis patients, by active participation in the collaboration among regional core centers, specialized medical institutions and central/local governments. In cooperation with the nationwide awareness-raising program, "Shitte Kan-en" project, Hepatitis Information Center and regional core centers have contributed to the synthesis and distribution of the hepatitis educational program to the young generations (7).

\section{Screening and diagnosis of viral hepatitis in Japan}

Testing for viral hepatitis is an initial step of the linkage to care for patients with hepatitis B or C. In Japan, national and local government share screening costs for testing hepatitis $\mathrm{B}$ and $\mathrm{C}$ for those residents who are over 40 years old (Figure 1). Thus, out-of-pocket expenses from examinees are free of charge or reduced to the minimum. From 2001 to 2014, approximately 17 million persons have taken a hepatitis virus test in this country. Test results for hepatitis B and hepatitis C are notified to patients, and positives are encouraged to visit medical institutions and to get registration to the follow-up system in some prefectures. Intensive medical examinations are necessary for positive test patients for the diagnosis of liver disease with active viremia, to determine whether they should be treated or not with anti-viral agents. For this purpose, medical expenses are covered by local governments for positive testers, which are even found at workplaces, and pre-surgical or maternal check-ups, who agree to participate in the follow-up program (Figure 1) (8).

\section{Linkage from diagnosis to treatment in viral hepatitis in Japan}

The nationwide questionnaire analysis on viral hepatitis testing in FY2017 disclosed that the screening rates of HBV or HCV were $71.0 \%$ and $61.6 \%$, respectively. Of particular importance, people who clearly remember having taken a hepatitis test were limited to $20.1 \%$ for HBV and $18.7 \%$ for HCV, respectively. This survey demonstrated that about $40 \%$ of the participants were unaware of test experience in FY2017. What is worse, even if the test results were positive, approximately $30 \%$ of the people were unaware of the test results and failed to seek medical institutions (9). Such a gap in the linkage to care for viral hepatitis should be one of biggest hurdles for viral hepatitis elimination in Japan.

Hepatitis medical care coordinators (HMCC) are specialized personnel who are expected to support patients and their families in every aspect of the cascade of care. Through the end of March 2019, 16,546 HMCCs were certified in Japan. Actual roles of HMCCs are the following: $i$ ) sharing updated information of viral hepatitis, ii) introduction to consultation services, encouraging to undergo examinations and treatment, etc., and iii) coordinating in promoting appropriate medical care. HMCCs with various occupations are working at regional core centers, specialized hospitals, public health centers, pharmacies and municipal offices (10). HMCCs are unique health professionals who could play significant roles in filling the gaps between diagnosis, treatment and care of viral hepatitis.

\section{Antiviral treatment in Japan - clinical guidelines and subsidy program}

In clinical practice in Japan, optimization of DAAs treatment has been done based on HCV genotypes, 


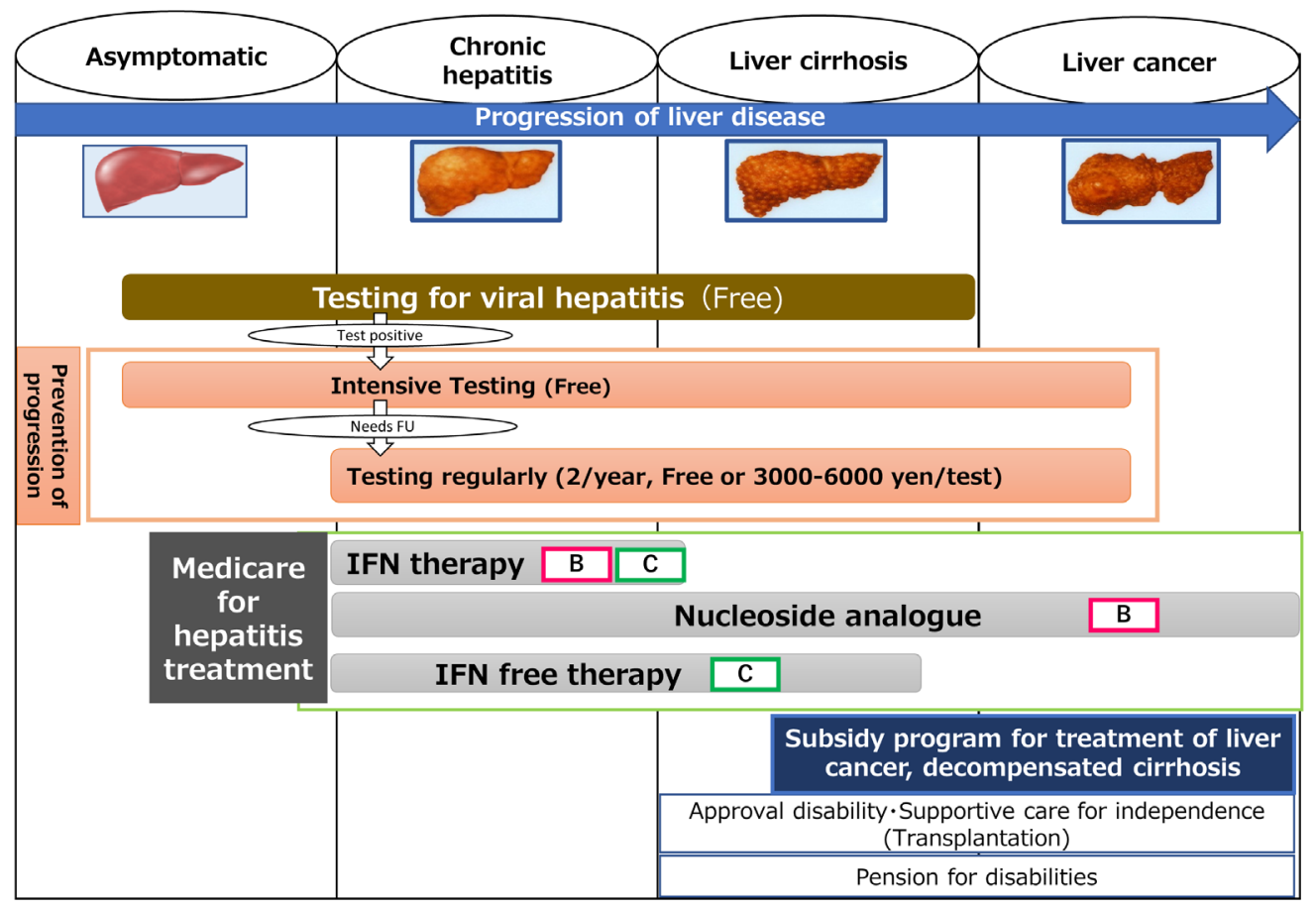

Figure 1. National Hepatitis Program in Japan. In Japan, lifelong support is provided to patients with viral hepatitis. People can take viral hepatitis test for free in most cases. If they are diagnosed as HBV or HCV positive, they can get more intensive examinations including ultrasonography, in order to decide whether they need anti-viral treatment. In the specialized institutions or regional core centers, they can get interferons or direct-acting antivirals, medical expenses, which are covered by special subsidy programs. From 2018, a special subsidy program for the treatment of liver cancer and decompensated cirrhosis was started. If the condition of patients deteriorates with progression to liver cirrhosis, they are supported by special pension programs. The format is adapted from the information from the Ministry of Health, Labor and Welfare in Japan.

stages of liver disease (chronic hepatitis or compensated/ decompensated cirrhosis), prior experience with DAAs and the pattern of resistance-associated substitutions (RAS) on treatment. Of particular importance, meticulous care is needed for the treatment of patients with prior DAA failure and decompensated liver cirrhosis. Such tailored DAA treatment is guided by the Guidelines for the management of hepatitis $C$ virus infection, updated and issued from Japan Society of Hepatology, which have been updated in pace with the registration of novel DAAs (11).

There are no barriers to prescribing antiviral drugs or DAAs to patients with hepatitis $\mathrm{C}$ with the public health insurance. In addition, for the treatment cost for chronic hepatitis B or C, drug prices for nucleotide analogues, interferon (IFN)-based treatment or IFN-free DAAs and examination expenses should be covered by the special program for viral hepatitis (Figure 1). The national and local government altogether cover the amount in excess of ten or twenty thousand yen (approximately 100-200 USD) of the cost of treatment (depending on the amount of tax payment) (8). As for the eligibility of using such a coverage program, the patients have to submit an application to the prefecture office with recommendation from a designated hepatologist or gastroenterologist $(12,13)$. The sustained viral response (SVR) rate using DAAs, including patients with decompensated cirrhosis, has been dramatically improved.

\section{Perspectives}

Recently, patients with new or re-infection with HCV are on the rise because of the expansion of persons who inject drugs in some countries, the trend of which has been most significant in younger generations. In order to overcome such tall barriers to eliminate viral hepatitis, the development of a long-awaited protective/ therapeutic $\mathrm{HCV}$ vaccine could be one of the remedies. Several beneficial advantages have prevailed in Japanese health care systems for patients with viral liver disease compared to those in other countries in the Western Pacific Region. In my personal opinion, Japan should take a lead in supporting implementation of a practical hepatitis action plan or education programs for healthcare workers, such as HMCCs, adjusted for each country where in need.

\section{Funding: None.}

Conflict of Interest: Tatsuya Kanto received lecture fee from AbbVie and Gilead Sciences.

\section{References}

1. World Health Organization. WHO Global hepatitis report, 2017. https://www.who.int/publications/i/item/globalhepatitis-report-2017 (accessed May 27, 2021). 
2. Stanaway JD, Flaxman AD, Naghavi M, et al. The global burden of viral hepatitis from 1990 to 2013: findings from the Global Burden of Disease Study 2013. Lancet. 2016; 388:1081-1088.

3. Tanaka J. Report on epidemiological studies to assess the status of hepatitis virus infection and to contribute to designing measurements against the elimination of viral hepatitis. Japan: MHLW scientific research subsidy, Research Project for Emergency Measures to Conquer Hepatitis FY2019. https://mhlw-grants.niph.go.jp/ node/61182 (accessed May 10, 2021). (in Japanese)

4. Ministry of Health, Labour and Welfare. Basic Act on Hepatitis Measures. http://www.japaneselawtranslation. go.jp/law/detail_main? $r e=\& v m=01 \& i d=1995$ (accessed March 31, 2021). (in Japanese)

5. Ministry of Health, Labour and Welfare. Basic Guidelines for Promotion of Control Measures for Hepatitis. https:// www.mhlw.go.jp/bunya/kenkou/kekkaku-kansenshou09/ pdf/hourei-27.pdf (accessed March 31, 2021). (in Japanese)

6. Setoyama H, Korenaga M, Kitayama Y, Oza N, Masaki N, Kanto T. Nationwide survey on activities of regional core centers for the management of liver disease in Japan: Cumulative analyses by the Hepatitis Information Center 2009-2017. Hepatol Res. 2020; 50:165-173.

7. Takeuchi Y, Ohara M, Kanto T. Nationwide awarenessraising program for viral hepatitis in Japan: the "Shitte kan-en" project. Glob Health Med. 2021. https://doi. org/10.35772/ghm.2021.01063

8. Korenaga $\mathrm{M}$ and Kanto T. Testing, diagnosis of viral hepatitis, and the follow-up policy in Japan. Glob Health Med. 2021. https://doi.org/10.35772/ghm.2021.01072

9. Ministry of Health, Labour and Welfare. FY2011 Report on the Current Extent of Hepatitis Testing. https://www.mhlw.go.jp/stf/houdou/2r9852000002gd4jatt/2r9852000002gd60.pdf (accessed May 10, 2021). (in Japanese)

10. Isoda H, Eguchi Y, Takahashi H. Hepatitis medical care coordinators: Comprehensive and seamless support for patients with hepatitis. Glob Health Med. 2021. https:// doi.org/10.35772/ghm.2021.01073

11. Tahata Y, Sakamori R, Takehara T. Treatment progress and expansion in Japan: From interferon to directacting antiviral. Glob Health Med. 2021. https://doi. org/10.35772/ghm.2021.01083

12. Setoyama H, Tanaka Y, Kanto T. Seamless support from screening to anti-HCV treatment and HCC/decompensated cirrhosis: Subsidy programs for HCV elimination. Glob Health Med. 2021. https://doi.org/10.35772/ ghm.2021.01079

13. Oza N, Isoda H, Ono T, Kanto T. Current activities and future directions of comprehensive hepatitis control measures in Japan: The supportive role of the Hepatitis Information Center in building a solid foundation. Hepatol Res. 2017; 47:487-496.

Received June 23, 2021; Revised September 21, 2021 ; Accepted October 4, 2021.

Released online in J-STAGE as advance publication October 16, 2021.

*Address correspondence to:

Tatsuya Kanto, The Research Center for Hepatitis and Immunology, National Center for Global Health and Medicine, 1-7-1, Kohnodai, Ichikawa, Chiba 272-8516, Japan.

E-mail:kantot@hospk.ncgm.go.jp 